\title{
Side-chain effect of organic semiconductors in OFET- based chemical sensors
}

\author{
Dapeng Liu, Yingli Chu, Xiaohan Wu and Jia Huang*
}

\begin{abstract}
Organic field-effect transistors (OFETs) offer great potential applications in chemical and biological sensing for homeland security, environmental monitoring, industry manufacturing, and medical/biological detection. Many studies concentrate on sensitivity and selectivity improvement of OFET-based sensors. We report four organic semiconductors with different alkyl side chain lengths but the same $\pi$-conjugated core structure for OFETs. Our work focuses on the molecular structure of organic semiconductors (OSCs). Alkyl side chains can hinder the diffusion of ammonia into the OSCs layer, which blocks the interaction between ammonia and conducting channel. The result also reveals the relationship between the alky chain and the film thickness in sensitivity control. These results are expected to be a guide to the molecular design of organic semiconductors and the choice of OSCs.
\end{abstract}

Keywords: organic field-effect transistors, chemical sensor, side alkyl chain

\section{INTRODUCTION}

Organic field-effect transistors (OFETs) have been investigated extensively for applications such as display drivers, radio frequency identification tags, and circuits of moderate complexity [1-6]. Another compelling application of OFET is chemical and biological sensing [7-12]. Sensors based on OFETs can be low-weight, low-cost, flexible, and miniaturized [13-18]. Analyte molecules can have various effects on organic semiconductors (OSCs), such as doping or quenching induced charge carrier density variation and dipole-induced trapping and retarding of charges [19-22]. These OSC/analyte interactions alter the threshold voltages and the mobilities of OFETs and lead to changes in the output source-drain current. Compared to inorganic devices, OSCs provide the possibility to operate sensors at room temperature without the need of heating, and the great freedom to tune charge carrier energies and analyte affinities through synthetic chemistry [23-27].

In the past decade, various approaches have been developed to tailor the sensing performances of OFETbased chemical sensors. Most of those approaches focused on designing OSC molecules with specific $\pi$-conjugated core structures $[28,29]$, bonding or depositing receptors on OSCs [30-32], modifying OSC film thickness [33,34], modulating OSC microstructures and morphologies $[35,36]$. However, the effect of OSC side chain length on OFET chemical sensor performance has not been sufficiently investigated.

For OSC molecules, the $\pi$-conjugated core structures define the energy band structure of the materials, whereas side chain of OSC also plays an important role. For example, alkyl-chain can promote OSC molecules to align in order, and improve the solubility of OSCs [37-39], while fluorinated alkyl chain in $n$-type OSC can improve the air stability of the compound [40]. Actually, the side chain in OSC not only affects OFET electronic characteristics, but can also impact to performance of chemical sensors based on OFETs. In this work, we systematically studied four OSCs with different alkyl side chain lengths but the same $\pi$-conjugated core structure. OFET sensors fabricated with these four OSCs exhibited distinguished sensitivity upon exposure to ammonium vapor, in terms of normalized current change and absolute current change. These results reveal the importance of selecting appropriate side chain for OSCs to meet the specific need of various chemical OFET sensors.

\section{EXPERIMENTAL SECTION}

Semiconductors synthesis

5,5'-bis(4-hexylphenyl)-2,2'-bithiophene (6PTTP6) was 
synthesized according to the previously reported process [41]. The precursor with various alkyl lengths $(0,2$ and 12) (bromide benzene, 4-bromo-ethylbenzene and 4bromo-dodecylbenzene) is used to synthesize 5,5'-diphenyl-2,2'-bithiophene (PTTP), 5,5'-bis(4-ethylphenyl)-2,2'bithiophene (2PTTP2) and 5,5'-bis(4-dodecylphenyl)2,2'-bithiophene (12PTTP12).

\section{OFETs fabrication and characterization}

Heavily $n$-type doped silicon substrates with a $500 \mathrm{~nm}$ thermally oxidized layer were successively cleaned by sonication in acetone and isopropanol for $30 \mathrm{~min}$. Then they were rinsed with deionized water and ethanol, dried by nitrogen flow. To optimize device performance, before evaporation, the silicon substrate was modified with orthotrichlorosilane (OTS) to form a self-assembled monolayer (SAM). Then the OSCs (PTTP, 2PTTP2, 6PTTP6 and 12PTTP12) layers were thermally evaporated on the OTS-treated silicon wafers at a rate of $0.3 \AA^{-1}$ and a pressure of $1 \times 10^{-4} \mathrm{~Pa}$. The substrate temperature was held constantly at $55^{\circ} \mathrm{C}$. The thickness of the OSCs layers was controlled with a quartz crystal microbalance. Finally, $75 \mathrm{~nm}$ Au electrodes were thermally evaporated on the OSCs layers to form a top-contact structure through a shadow mask with a channel length of $50 \mu \mathrm{m}$ and a width of $15 \mathrm{~mm}$.

The structure and surface morphologies of OSCs films were characterized by X-ray diffraction (XRD) (DX2700A, Dandong Haoyuan Instrument Com. Ltd.) and atomic force microscopy (AFM) (Bruker Dimension Icon, Bruker Corporation), respectively. The evaluations of the OFETs were carried out by using a Keithley 4200 semiconductor characterization system connected to a homemade vapor test chamber. Devices were measured in a test chamber filled with pure nitrogen. Then a certain amount of ammonia was injected into the chamber, in which the concentration of ammonia was fixed at $1 \mathrm{ppm}$.

\section{RESULTS AND DISCUSSION}

\section{$\mathrm{X}$-ray diffraction and atomic force microscope}

Fig. 1a shows the chemical structures of PTTP, 2PTTP2, 6PTTP6 and 12PTTP12. The as-fabricated OFETs have bottom-gate top-contact (BGTC) configuration.

The XRD characterization of four OSC films in Fig. 1b proves that the packing modes of 2PTTP2, 6PTTP6 and 12PTTP12 on silicon oxide surface are all uprightstanding packing style. The first intense Bragg peaks of 2PTTP2 and 6PTTP6 correspond to an interlayer spacing of 18.02 and $29.42 \AA$, respectively. The first Bragg peak of

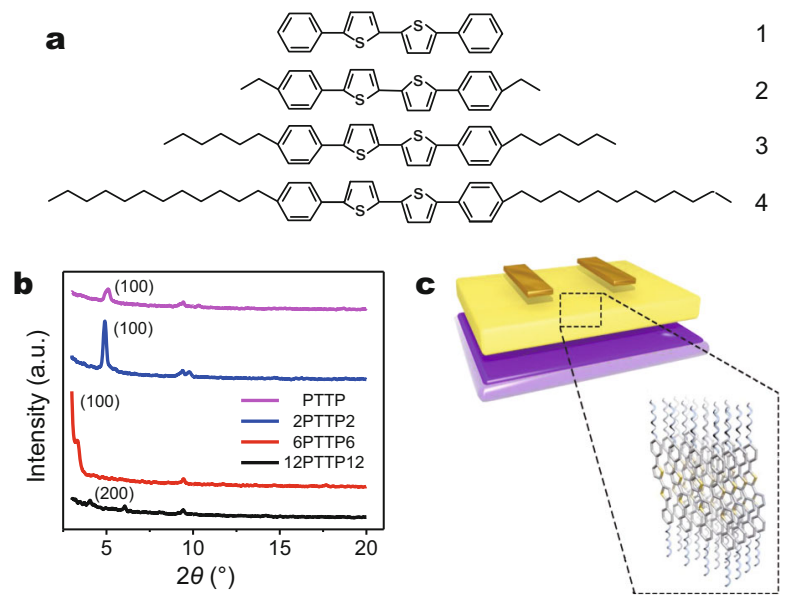

Figure 1 (a) Chemical structure of $\operatorname{NPTTPN}(\mathrm{N}=0,2,6,12)$. (b) XRD patterns of four OSC films. (c) The configuration of OFET device.

12PTTP12 film is not observed because the angle referring to the peaks is beyond the measurement range. The 12PTTP12 interlayer spacing of $43.32 \AA$ was obtained from the $2 \theta$ value of the (200) peak. XRD for PTTP film shows that the (100) peak shifts to slightly higher value than 2PTTP2 due to the longer molecular length of 2PTTP2 than that of PTTP. The low intensity of (100) peak reveals low crystallinity of PTTP film.

In the first batch, four OSC films were prepared by evaporating same amount of OSCs by mass on the wafer with same sizes, which are called as equal-mass films. The mass of OSCs deposited was controlled with a quartz crystal microbalance. All four devices have the same reading on the quartz crystal microbalance when the evaporation was stopped. The second batch contains the four OSC films that consist of same number of OSC monolayers (19 monolayers), called as equal-layer films. The number of the other three OSC monolayers was fixed at 19. According to Table 1, the mass of PTTP and 2PTTP2 evaporated, controlled with a quartz crystal microbalance, was scaled down at the proportion the same as the ratio of relative molecular weight of the OSC and 6PTTP6. The mass of 12PTTP12 molecules deposited was increased at the same proportion as the ratio of relative molecular weight of 12PTTP12 and 6PTTP6. To further investigate the microstructure of OSC films, the equalmass films were characterized by AFM. Fig. 2b-d, f-h show the morphologies of the 2PTTP2, 6РTTP6, 12PTTP12 film, which reveals they were consisting of monolayer plates through a layer-by-layer growth by thermal evaporation with the function of alkyl chain [42]. The morphology of PTTP film in Fig. 2a, e is different from the morphology of the other three OSCs, which is 
Table 1 The physical parameters of the equal-mass OSC films

\begin{tabular}{|c|c|c|c|c|c|c|}
\hline Organic semiconductor & $\begin{array}{l}\text { Relative molecular } \\
\text { weight }\left(\mathrm{g} \mathrm{mol}^{-1}\right)\end{array}$ & $\begin{array}{l}\text { Film thickness } \\
(\mathrm{nm})\end{array}$ & Space of monolayer & $\begin{array}{l}\text { Number of } \\
\text { monolayers }\end{array}$ & $\begin{array}{c}\text { Normalized } I_{\mathrm{SD}} \\
\text { change }\end{array}$ & $\begin{array}{l}\text { Absolute } I_{\mathrm{SD}} \\
\text { change }(\mu \mathrm{A})\end{array}$ \\
\hline PTTP & 318 & $84 \mathrm{~nm}$ & 17.18 & 49 & $-46 \%$ & -0.3 \\
\hline 2РTTP2 & 376 & $51 \mathrm{~nm}$ & 18.02 & 28 & $-24 \%$ & -39 \\
\hline 6РTTP6 & 488 & $55 \mathrm{~nm}$ & 29.42 & 19 & $-33 \%$ & -33 \\
\hline 12РTTP12 & 656 & $32 \mathrm{~nm}$ & 43.32 & 7.0 & $-4.0 \%$ & -6.0 \\
\hline
\end{tabular}

a

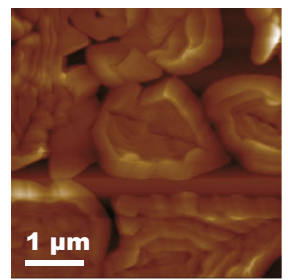

e

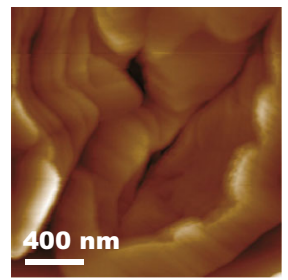

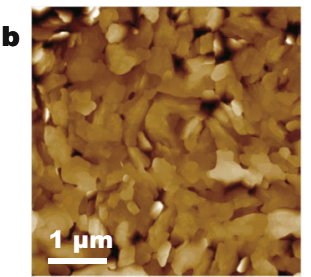

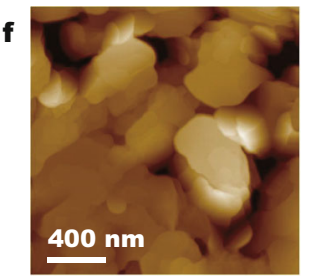

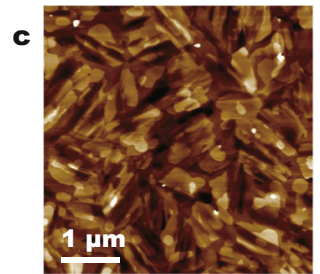
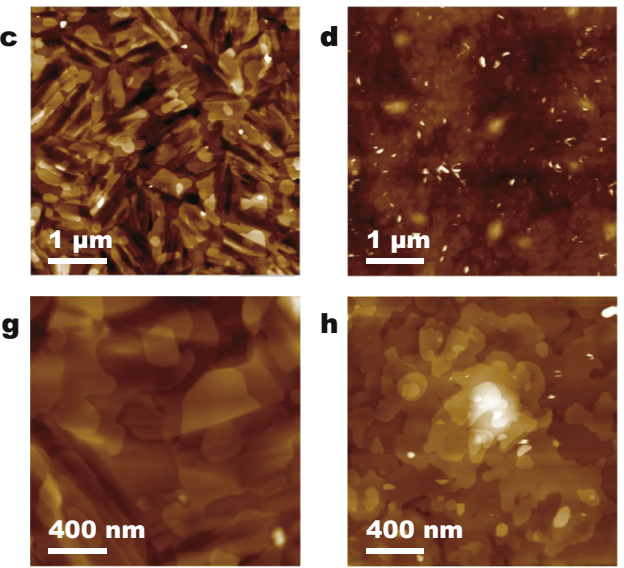

Figure 2 AFM images of thermally evaporated PTTP (a, e), 2PTTP2 (b, f), 6PTTP6 (c, g), and 12 PTTP12 (d, h) films.

due to missing alkyl chain in PTTP molecules to induce the layer-by-layer growth of OSC films. The thickness of equal- weight films (PTTP, 2PTTP2, 6PTTP6 and 12PTTP12) were also measured by AFM (see in Table 1), which reveals different thicknesses in four OSC films due to different relative molecular masses, different molecular lengths and different densities. The highest thickness of the films refers to the lightest molecule PTTP. The thickness of 2PTTP2 and 6PTTP6 film is comparable, while the 12PTTP12 film only has $32 \mathrm{~nm}$ in thickness. The number of monolayer is calculated through dividing the film thickness by the space of monolayer, which is taken into consideration including the film thickness and the length of molecular side alkyl chain to investigate the effects on sensing performance. Although the molecules of different organic semiconductors stand upright on the surface, the angles between the molecules and the substrate surface can be much different, leading to that the numbers of the molecules per unit area are different. This explains that the films of different organic semiconductors seem to be not equal mass based on the values shown in Table 1.

\section{Electronic performances and sensing tests}

On the basis of the morphology characterization of the OSC films, to investigate the sensing performance of the equal-mass OFETs with various alkyl chains, the transfer curves of the devices were cycling tested in a homemade chamber before and after the injection of $\mathrm{NH}_{3}$ vapors at a concentration of $1 \mathrm{ppm}(v / v)$. All devices work well before the $\mathrm{NH}_{3}$ sensing tests (Fig. S1). The normalized source-drain current $\left(I_{\mathrm{SD}} / I_{\mathrm{SD}, 0}\right)$ was extracted from the transfer characteristic curves and plotted as a function of testing time in Fig. $3 \mathrm{a}\left(V_{\mathrm{SD}}=-60 \mathrm{~V}, V_{\mathrm{G}}=-60 \mathrm{~V}\right)$. The $I_{\mathrm{SD}}$ of all four devices decreased right after the device was exposed to $\mathrm{NH}_{3}$ vapor. The PTTP OFET exhibited the highest response with $46 \%$ current decrease, because the $\mathrm{NH}_{3}$ molecules can directly interact with the charge carriers in the conduction channel without the block of the alkyl chain. After the $1 \mathrm{ppm} \mathrm{NH}_{3}$ vapor was injected, the 2PTTP2 and 6PTTP6 OFET exhibited 24\% and 33\% current decrease, respectively, both of which are larger than the $4 \%$ current reduction of the 12PTTP12 OFET. The 12PTTP12 molecule has the longest alkyl chain. When $\mathrm{NH}_{3}$ molecules approach to the OSC film, the long alkyl chain enlarges the path for the $\mathrm{NH}_{3}$ to interact with charges. Compared to the 12PTTP12 OFET, more $\mathrm{NH}_{3}$ molecules interact with the charges in 2PTTP2 and 6PTTP6 OFET with shorter alkyl chains. Fig. 3b, c plot the $I_{\mathrm{SD}}$ and the absolute change of source-drain current $\left(I_{\mathrm{SD}}-I_{\mathrm{SD}, 0}\right)$ under $V_{\mathrm{G}}=-60 \mathrm{~V}$ and $V_{\mathrm{SD}}=-60 \mathrm{~V}$ as the function of testing time. The $I_{\mathrm{SD}}$ of 2PTTP2 OFET and 

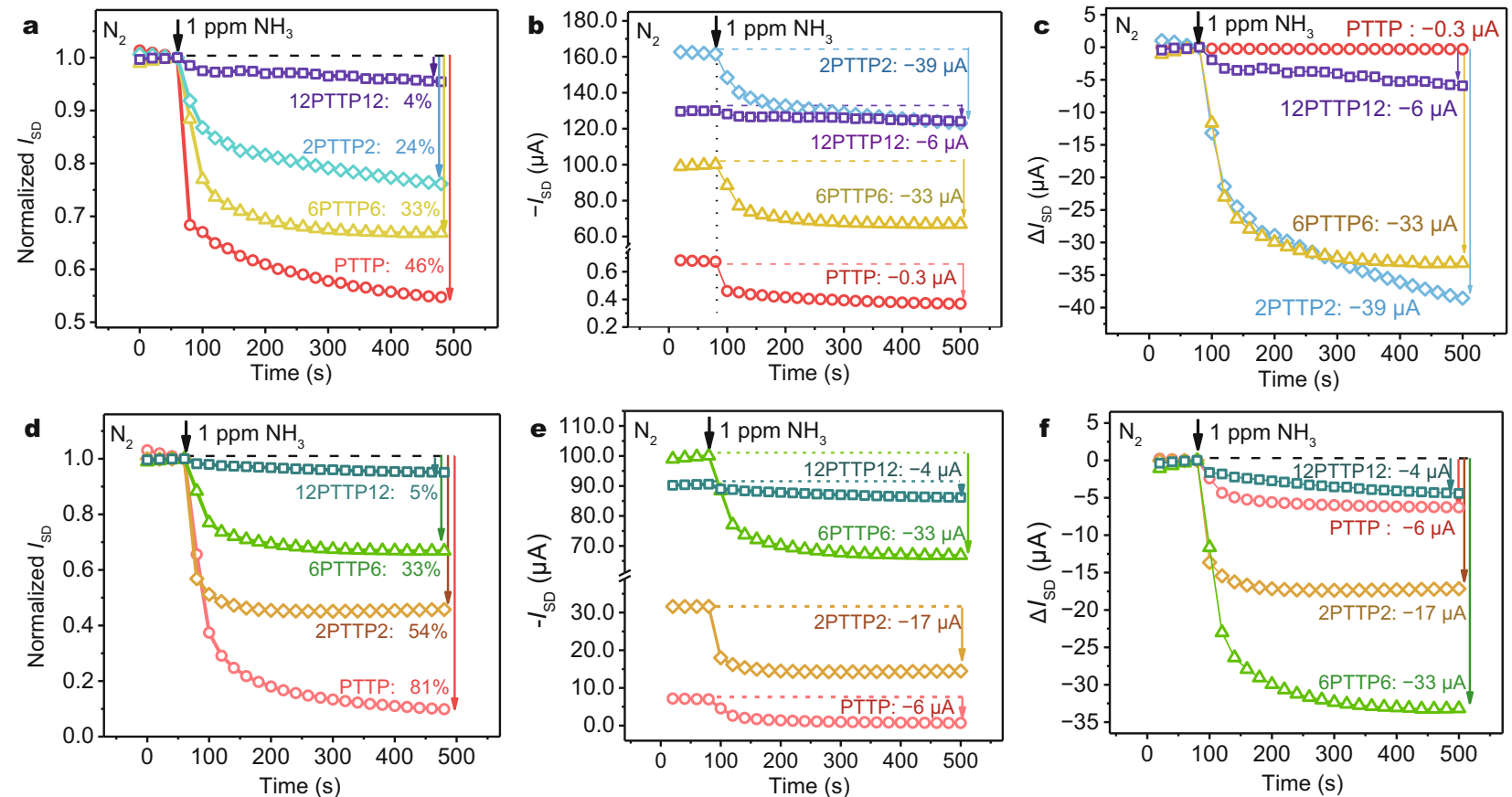

Figure 3 Response of four OFETs on exposure to $1 \mathrm{ppm} \mathrm{NH}_{3}$ : percentage $I_{\mathrm{SD}}$ change for the devices with equal mass (a) and equal layers (d). Absolute $I_{\mathrm{SD}}$ change for the devices with equal mass $(\mathrm{b}, \mathrm{c})$ and equal layers $(\mathrm{e}, \mathrm{f}) .\left(V_{\mathrm{SD}}=-60 \mathrm{~V}, V_{\mathrm{G}}=-60 \mathrm{~V}\right)$

Table 2 The physical parameters of the equal-layer OSC films

\begin{tabular}{ccccccc}
\hline Organic semiconductor & $\begin{array}{c}\text { Relative molecular } \\
\text { weight }\left(\mathrm{g} \mathrm{mol}^{-1}\right)\end{array}$ & $\begin{array}{c}\text { Film thickness } \\
(\mathrm{nm})\end{array}$ & $\begin{array}{c}\text { Space of } \\
\text { monolayer }(\AA)\end{array}$ & $\begin{array}{c}\text { Number of } \\
\text { monolayers }\end{array}$ & $\begin{array}{c}\text { Normalized } I_{\mathrm{SD}} \\
\text { change }\end{array}$ & $\begin{array}{c}\text { Absolute } I_{\mathrm{SD}} \\
\text { change }(\mu \AA)\end{array}$ \\
\hline PTTP & 318 & $33 \mathrm{~nm}$ & 17.18 & 19 & $-81 \%$ & -6.0 \\
2PTTP2 & 376 & $35 \mathrm{~nm}$ & 18.02 & 19 & $-54 \%$ & -17 \\
6PTTP6 & 488 & $55 \mathrm{~nm}$ & 29.42 & 19 & $-33 \%$ & -33 \\
12PTTP12 & 656 & $86 \mathrm{~nm}$ & 43.32 & 19 & $-5.0 \%$ & -4.0 \\
\hline
\end{tabular}

6PTTP6 OFET were $160 \mu \mathrm{A}$ and $100 \mu \mathrm{A}$, and they exhibited obvious response with more than $33 \mu \mathrm{A}$ current decrease, while the response of the 12PTTP12 OFET was negligible with only $6 \mu \mathrm{A}$ current decrease. For the PTTP OFET, although the device showed $46 \%$ current decrease, the absolute current change was only $-0.3 \mu \mathrm{A}$ due to the low output current of the device. The lowest intensity (100) peak of PTTP reveals the lowest crystallinity in the PTTP film. The large gaps between the crystal particles in PTTP film can be observed in AFM images. The lowest crystallinity and the large gaps determine the lowest current in PTTP devices. When the absolute current change is the most important parameter to measure the device sensitivity, OFETs with relatively high output current are appropriate, such as 2PTTP2 OFET and 6PTTP6 OFET. Their absolute current decrease was over $30 \mu \mathrm{A}$. However, OFETs with over long alkyl chains
(12PTTP12 OFET, $-6 \mu \mathrm{A}$ in absolute current change) exhibit small change of the absolute current to analyte even at high output current.

The equal-mass 6PTTP6 OFET has 19 monolayers, while the 2PTTP2 OFET has 28 monolayers. In Fig. 3a, the response of 6PTTP6 OFET to $1 \mathrm{ppm} \mathrm{NH}_{3}$ is $33 \%$ current decrease, larger than the response of 2PTTP2 OFET at $24 \%$ current decrease, which indicates that the amount of monolayer has a significant impact on the interaction of $\mathrm{NH}_{3}$ molecules with charges according to the parameter of 2PTTP2 and 6PTTP6 film in Table 1. With the comparison between the parameters of same molecules in Table 1 and Table 2, the devices with less monolayers (PTTP, 2PTTP2) show larger response than the device with more monolayers. To further compare the sensing performance of OFETs with different side chains but the same number of monolayers, the equal-layer OSC 

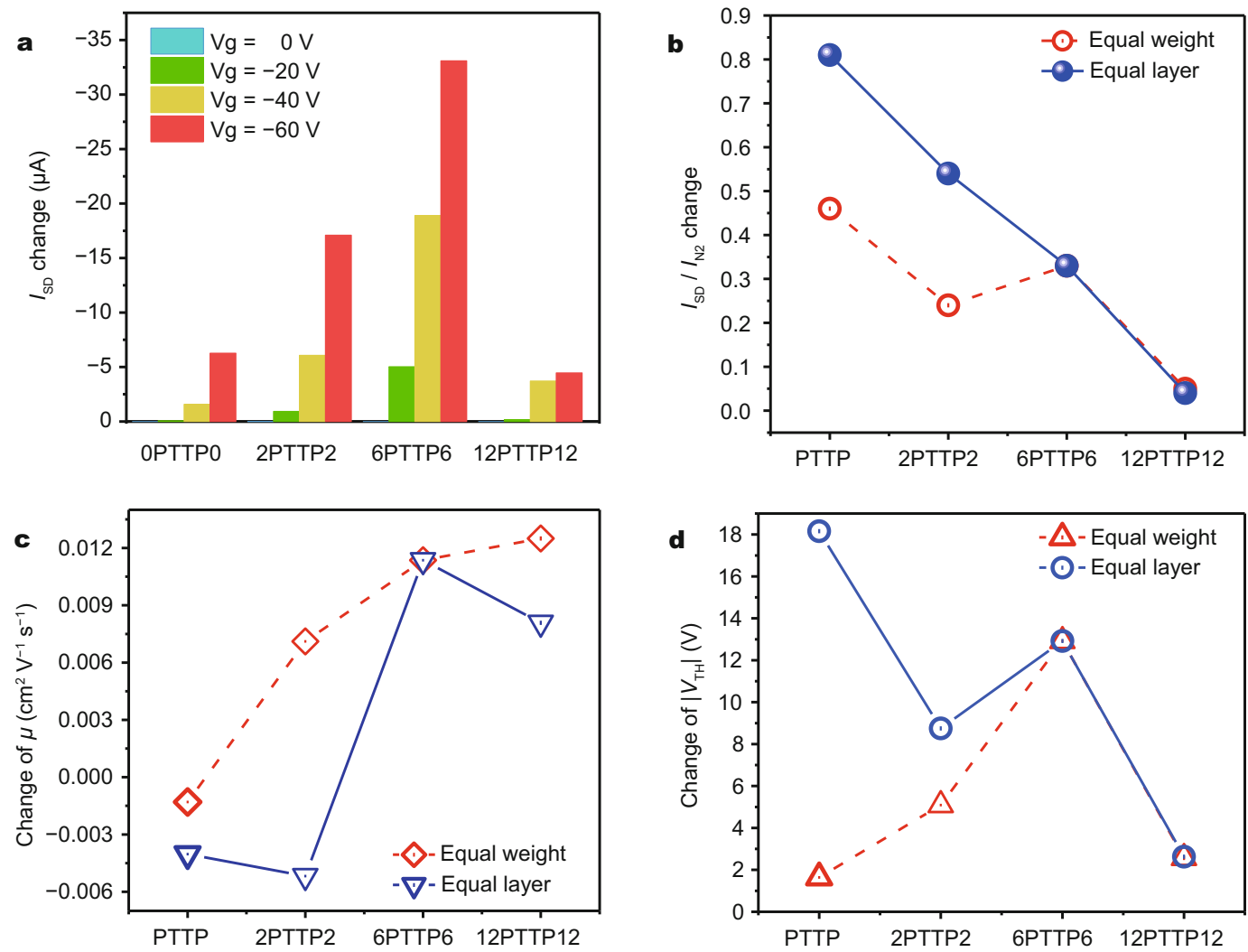

Figure 4 (a) Absolute $I_{\mathrm{SD}}$ change for the devices in equal layers at various $V_{\mathrm{G}}$ from 0 to $-60 \mathrm{~V}$. (b) Normalized $I_{\mathrm{SD}}$ change as a function of the length of alkyl side chains. (c) Mobility ( $\mu$ ) of four equal-layer and equal-mass devices before and after exposure to 1 ppm $\mathrm{NH}_{3}$. (d) $\mathrm{Change}$ of threshold voltages $\left(V_{\mathrm{th}}\right)$ on exposure to $1 \mathrm{ppm} \mathrm{NH}_{3}$ of equal-mass and equal-layer devices. $\left(V_{\mathrm{SD}}=-60 \mathrm{~V}\right)$

OFETs were fabricated and tested in the same condition. All OSC films have 19 monolayers. Fig. 3d plots the normalized $I_{\mathrm{SD}}$ of the transfer curves as the function of testing time. Fig. 3e, f were the absolute variation of $I_{\mathrm{SD}}$ of four OFETs as the function of testing time. The film thickness of PTTP and 2PTTP2 were decreased by evaporating fewer OSC molecules on the wafer, which improves their sensitivity to the $1 \mathrm{ppm} \mathrm{NH}_{3}$ [33]. The PTTP OFET was largely quenched, with the $I_{\mathrm{SD}}$ decreased to less than $20 \%$ of its original value ( $81 \%$ current decrease), but the reduction of $I_{\mathrm{SD}}$ in PTTP was as low as $-6 \mu \mathrm{A}$, which is due to the low initial $I_{\mathrm{SD}}$ of PTTP OFET. The response of 2PTTP2 OFET to $1 \mathrm{ppm} \mathrm{NH}_{3}$ is $54 \%$ current decrease, larger than the response of the 2PTTP2 OFET in the first batch. More 12PTTP12 molecules were deposited on the wafer, which increased the film thickness and decreased its initial $I_{\mathrm{SD}}$ in $\mathrm{N}_{2}$ from 130 to $90 \mu \mathrm{A}$. The $12 \mathrm{PTTP} 12$ OFET still showed negligible response with $I_{\mathrm{SD}}$ decreased by $4 \mu \mathrm{A}$ upon exposure to $1 \mathrm{ppm} \mathrm{NH}_{3}$.

The changes of $I_{\mathrm{SD}}$ of four OFETs with equal layer at various $V_{\mathrm{G}}$ were summarized in Fig. 4a. The 6PTTP6
OFET showed higher response than the other three OFETs when the $V_{\mathrm{G}}$ was increased to $-20 \mathrm{~V}$. The $I_{\mathrm{SD}}$ of PTTP OFET was the lowest due to its poor ordered arrangement of PTTP molecules, which limited its output current. As the alkyl chain length increased, more OSC molecules arranged in a fixed direction on the OTSmodified silicon wafer, resulting in better $\pi-\pi$ stacking, higher degree of crystallinity and the increase of output current. However, the longest alkyl chain of 12PTTP12 obstructed the interaction of $\mathrm{NH}_{3}$ with charges, which led to the lowest sensitivity of 12PTTP12 OFET to $1 \mathrm{ppm}$ $\mathrm{NH}_{3}$. Fig. $4 \mathrm{~b}$ plots the normalized $I_{\mathrm{SD}}$ change of OFETs with equal mass (red line) and equal layer (blue line) as the function of alkyl chain length under $V_{\mathrm{SD}}=-60 \mathrm{~V}$. The charge mobility $(\mu)$ and the change of threshold voltage $\left(V_{\text {th }}\right)$ of the four devices with equal mass and equal layer were extracted from the transfer characteristic curves and plotted in Fig. 4c, d under $V_{\mathrm{SD}}=-60 \mathrm{~V}$. The change of OFET mobility after the injection of $1 \mathrm{ppm} \mathrm{NH}_{3}$ is negligible, but the change of threshold voltage is significant. The 6PTTP6 molecules with appropriative alkyl chain 
length forms the film with high order of molecular arrangement and effective response to $1 \mathrm{ppm} \mathrm{NH}_{3}$.

\section{CONCLUSIONS}

The OSC films with varying alkyl chain length were prepared and characterized. The electronic performance and sensitivity to $\mathrm{NH}_{3}$ of OFETs prepared with the four OSC molecules were tested. It was found that alkyl chain induced layer-by-layer growth of OSC films. The existence of alkyl chains hindered the interaction of $\mathrm{NH}_{3}$ molecules with charges in the conduction channel of OSC film (Fig. S2). OSC molecules without alkyl side chains and OSC molecules with short alkyl chains stacked in poor order during the growth of OSC films, which decreased the output current and the change of absolute $I_{\mathrm{SD}}$. However, higher normalized current response in these OFETs can be observed, because $\mathrm{NH}_{3}$ molecules can easily interact with the charges in the conduction channel of these OFETs. Long alkyl chains contributed to good arrangement of OSC molecules which increase the $I_{\mathrm{SD}}$ but hindered the interaction of gas molecules with charges, resulting in the reduction of sensitivity. In conclusion, we showed the differences in molecular structure can lead to significant effects during the growth of OSC by thermal evaporation and the sensitivity test of the OSC film to gas molecules. It was confirmed that the optimized alkyl chain with appropriate length enhanced the molecular stacking and increased the output current, which results in more charge carriers to interact with analyte. The desired length of alkyl chains in OSC molecules depends on the requirement of OFET-based sensors of different applications. When the normalized response is considered as a key parameter, OSCs with short chain are preferred materials of choices. When the absolute current change is required, the devices with high output current are preferred, and OSCs with long side chain length would be better choices. When the OSC side chains are too long, the side chain might hinder the interaction of analyte molecules with charges in the conduction channel, resulting in both low absolute current change and low normalized response, although the device exhibits high output current. Our work is expected to be the guidance for molecular design and choosing for preparing highperformance OFET-based chemical sensors.

Received 19 July 2017; accepted 11 September 2017; published online 29 September 2017

1 Katz HE, Huang J. Thin-film organic electronic devices. Annu Rev Mater Res, 2009, 39: 71-92

2 Crone B, Dodabalapur A, Lin YY, et al. Large-scale complementary integrated circuits based on organic transistors. Nature, 2000, 403: 521-523

3 Rotzoll R, Mohapatra S, Olariu V, et al. Radio frequency rectifiers based on organic thin-film transistors. Appl Phys Lett, 2006, 88: 123502

4 Guo Y, Yu G, Liu Y. Functional organic field-effect transistors. Adv Mater, 2010, 22: 4427-4447

5 Mei J, Diao Y, Appleton AL, et al. Integrated materials design of organic semiconductors for field-effect transistors. J Am Chem Soc, 2013, 135: 6724-6746

6 Klauk H, Zschieschang U, Pflaum J, et al. Ultralow-power organic complementary circuits. Nature, 2007, 445: 745-748

7 Hammock ML, Chortos A, Tee BCK, et al. 25th anniversary article: the evolution of electronic skin (e-skin): a brief history, design considerations, and recent progress. Adv Mater, 2013, 25: 59976038

8 Kang B, Jang M, Chung Y, et al. Enhancing 2D growth of organic semiconductor thin films with macroporous structures via a smallmolecule heterointerface. Nat Commun, 2014, 5: 4752

9 Zhang C, Chen P, Hu W. Organic field-effect transistor-based gas sensors. Chem Soc Rev, 2015, 44: 2087-2107

10 Wu X, Ma Y, Zhang G, et al. Thermally stable, biocompatible, and flexible organic field-effect transistors and their application in temperature sensing arrays for artificial skin. Adv Funct Mater, 2015, 25: 2138-2146

11 Roberts ME, Sokolov AN, Bao Z. Material and device considerations for organic thin-film transistor sensors. J Mater Chem, 2009, 19: 3351

12 Someya T, Pal B, Huang J, et al. Organic semiconductor devices with enhanced field and environmental responses for novel applications. MRS Bull, 2008, 33: 690-696

13 Wang JZ, Gu J, Zenhausern F, et al. Low-cost fabrication of submicron all polymer field effect transistors. Appl Phys Lett, 2006, 88: 133502

14 Muccini M. A bright future for organic field-effect transistors. Nat Mater, 2006, 5: 605-613

15 Kaltenbrunner M, Sekitani T, Reeder J, et al. An ultra-lightweight design for imperceptible plastic electronics. Nature, 2013, 499: 458-463

16 Trung TQ, Lee NE. Flexible and stretchable physical sensor integrated platforms for wearable human-activity monitoringand personal healthcare. Adv Mater, 2016, 28: 4338-4372

17 Wang H, Liu H, Zhao Q, et al. Three-component integrated ultrathin organic photosensors for plastic optoelectronics. Adv Mater, 2016, 28: 624-630

18 Qian Y, Zhang X, Qi D, et al. Thin-film organic semiconductor devices: from flexibility to ultraflexibility. Sci China Mater, 2016, 59: 589-608

19 Torsi L, Dodabalapur A, Sabbatini L, et al. Multi-parameter gas sensors based on organic thin-film-transistors. Sensors Actuators B-Chem, 2000, 67: 312-316

20 Someya T, Dodabalapur A, Huang J, et al. Chemical and physical sensing by organic field-effect transistors and related devices. Adv Mater, 2010, 22: 3799-3811

21 Crone B, Dodabalapur A, Gelperin A, et al. Electronic sensing of vapors with organic transistors. Appl Phys Lett, 2001, 78: 22292231

22 Duarte D, Sharma D, Cobb B, et al. Charge transport and trapping in organic field effect transistors exposed to polar analytes. Appl Phys Lett, 2011, 98: 133302 
23 Kobaisi MA, Bhosale SV, Latham K, et al. Functional naphthalene diimides: synthesis, properties, and applications. Chem Rev, 2016, 116: 11685-11796

24 Segura JL, Juárez R, Ramos M, et al. Hexaazatriphenylene (HAT) derivatives: from synthesis to molecular design, self-organization and device applications. Chem Soc Rev, 2015, 44: 6850-6885

25 Sokolov AN, Tee BCK, Bettinger CJ, et al. Chemical and engineering approaches to enable organic field-effect transistors for electronic skin applications. Acc Chem Res, 2012, 45: 361-371

26 Torsi L, Farinola GM, Marinelli F, et al. A sensitivity-enhanced field-effect chiral sensor. Nat Mater, 2008, 7: 412-417

27 Feng L, Dong H, Li Q, et al. Tuning crystal polymorphs of a $\pi$ extended tetrathiafulvalene-based cruciform molecule towards high-performance organic field-effect transistors. Sci China Mater, 2017, 60: 75-82

28 Coropceanu V, Cornil J, da Silva Filho DA, et al. Charge transport in organic semiconductors. Chem Rev, 2007, 107: 926-952

29 Horowitz G. Organic field-effect transistors. Adv Mater, 1998, 10: 365-377

30 Huang J, Ng AL, Piao Y, et al. Covalently functionalized doublewalled carbon nanotubes combine high sensitivity and selectivity in the electrical detection of small molecules. J Am Chem Soc, 2013, 135: 2306-2312

31 See KC, Becknell A, Miragliotta J, et al. Enhanced response of nchannel naphthalenetetracarboxylic diimide transistors to dimethyl methylphosphonate using phenolic receptors. Adv Mater, 2007, 19: 3322-3327

32 Zheng G, Patolsky F, Cui Y, et al. Multiplexed electrical detection of cancer markers with nanowire sensor arrays. Nat Biotechnol, 2005, 23: 1294-1301

33 Li L, Gao P, Baumgarten M, et al. High performance field-effect ammonia sensors based on a structured ultrathin organic semiconductor film. Adv Mater, 2013, 25: 3419-3425

34 Huang J, Sun J, Katz HE. Monolayer-dimensional 5,5'-bis(4-hexylphenyl)-2,2'-bithiophene transistors and chemically responsive heterostructures. Adv Mater, 2008, 20: 2567-2572

35 Kwon OS, Park SJ, Lee JS, et al. Multidimensional conducting polymer nanotubes for ultrasensitive chemical nerve agent sensing. Nano Lett, 2012, 12: 2797-2802

36 Lu J, Liu D, Zhou J, et al. Porous organic field-effect transistors for enhanced chemical sensing performances. Adv Funct Mater, 2017, 27: 1700018

37 Mei J, Bao Z. Side chain engineering in solution-processable conjugated polymers. Chem Mater, 2014, 26: 604-615

38 El Labban A, Warnan J, Cabanetos C, et al. Dependence of crystallite formation and preferential backbone orientations on the side chain pattern in PBDTTPD polymers. ACS Appl Mater Interfaces, 2014, 6: 19477-19481

39 Back JY, An TK, Cheon YR, et al. Alkyl chain length dependence of the field-effect mobility in novel anthracene derivatives. ACS Appl Mater Interfaces, 2015, 7: 351-358

40 Wang C, Qin Y, Sun Y, et al. Thiophene-diketopyrrolopyrrolebased quinoidal small molecules as solution-processable and airstable organic semiconductors: tuning of the length and branching position of the alkyl side chain toward a high-performance nchannel organic field-effect transistor. ACS Appl Mater Interfaces, 2015, 7: 15978-15987

41 Mushrush M, Facchetti A, Lefenfeld M, et al. Easily processable phenylene-thiophene-based organic field-effect transistors and solution-fabricated nonvolatile transistor memory elements. J Am Chem Soc, 2003, 125: 9414-9423

42 Bao Z and Locklin J (eds.). Organic field-effect transistors. New York: CRC Press, 2007

Acknowledgements This work was financially supported by the National Natural Science Foundation of China (21302142 and 51603151), the National Key Research and Development Program of China (2017YFA0103900 and 2017YFA0103904), the 1000 Youth Talent Plan, and the Fundamental Research Funds for the Central Universities of China.

Author contributions Liu D and Huang J designed the devices and experiments; Chu Y synthesized the organic semiconductors; Liu D performed the experiments and analyzed the data; Liu $\mathrm{D}, \mathrm{Wu} \mathrm{X}$ and Huang $J$ wrote the paper.

Conflict of interest The authors declare that they have no conflict of interest.

Supplementary information The transfer output current of all devices are available in the online version of the paper. 


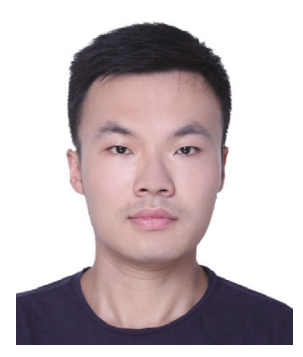

Dapeng Liu received his bachelor's degree from the School of Materials Science and Engineering at Tongji University, Shanghai, China. He is currently a PhD student in the School of Materials Science and Engineering, Tongji University. His main research area includes sensors based on organic semiconductor.

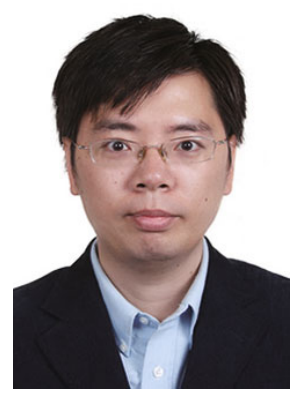

Jia Huang is a professor of materials science and engineering at Tongii University, Shanghai, China. He received the BSc degree in materials science and engineering from the University of Science and Technology of China, Hefei, China, MSc degree in applied science from the College of William \& Mary, Williamsburg, VA, USA, and PhD degree in materials science and engineering from Johns Hopkins University, Baltimore, MD, USA. His researches focus on organic semiconductors, flexible electronics, chemical and biological sensors, thin-film transistors, and energy related materials.

\section{有机半导体侧链对基于有机场效应晶体管的化学传感器性能的影响}

刘大鹏, 禇莹莉, 吴小晗, 黄佳 ${ }^{*}$

摘要 有机场效应晶体管在化学和生物传感、国土安全、环境监测、工业生产、医疗生物检测中具有很大的应用前景. 如何提高基于有 机场效应晶体管传感器的灵敏度和选择性的研究已有很多报导. 本文用四种具有不同长度的烷基侧链和相同 $\pi-\pi$ 共轭结构的有机半导体 来制备有机场效应晶体管, 集中研究有机半导体的分子结构. 烷基侧链可以减缓氨气在有机半导体层中的扩散, 阻止氨气和导电通道之间 的相互作用. 研究结果揭示了改变烷基侧链长度和薄膜厚度可以调控传感器的灵敏度, 这些结果有助于指导有机半导体材料的分子设计 和种类选择. 